\title{
G stemsem \\ Retention and Loss of PIT Tags and Implanted VHFs and Bio-Loggers in the Eurasian Beaver
}

\author{
Martin Mayer ( $\nabla$ martin.mayer@ecos.au.dk) \\ University of South-Eastern Norway \\ Marianne Lian \\ Inland Norway University of Applied Sciences
}

\section{Boris Fuchs}

Inland Norway University of Applied Sciences

\section{Christian A. Robstad}

University of South-Eastern Norway

\section{Alina L. Evans}

Inland Norway University of Applied Sciences

\section{Kathryn L. Perrin}

Center for Zoo and Wild Animal Health, Copenhagen Zoo

Eva M. Greunz

Center for Zoo and Wild Animal Health, Copenhagen Zoo

Timothy G. Laske

University of Minnesota

Jon M. Arnemo

Inland Norway University of Applied Sciences

Frank Rosell

University of South-Eastern Norway

\section{Research Article}

Keywords: animal welfare, body temperature logger, Castor fiber, heart rate logger, surgery

Posted Date: February 3rd, 2022

DOI: https://doi.org/10.21203/rs.3.rs-1285711/v1

License: (9) This work is licensed under a Creative Commons Attribution 4.0 International License. Read Full License 


\section{Abstract \\ Background}

Passive integrated transponder devices (PIT tags) are a valuable tool for individual identification of animals. Similarly, the surgical implantation of transmitters and bio-loggers can provide useful data on animal location, physiology and behavior. However, to avoid unnecessary recapture and related stress of study animals, PIT tags and bio-loggers should function reliably for long periods of time. Here, we evaluated the retention of PIT tags, and of very high frequency (VHF) transmitters and bio-loggers that were either implanted subcutaneously or into the peritoneal cavity of Eurasian beavers (Castor fiber).

\section{Results}

Over a 21-year period, we implanted PIT tags in 456 individuals and failed to detect a PIT tag in 30 cases, consisting of 26 individuals ( $6 \%$ of individuals). In all instances, we were still able to identify the individual due to the presence of unique ear tag numbers and tail scars. Moreover, we implanted $6 \mathrm{VHFs}$, 36 body temperature loggers and 21 heart rate loggers in 28 individuals, and experienced frequent loss of temperature loggers (at least 6 of 23 recaptured beavers) and heart rate loggers (10 of 18 recaptured beavers). No VHFs were lost in 2 recaptured beavers.

\section{Conclusions}

Possible causes for PIT tag loss (or non-detection) were incorrect implantation, migration of the tag within the body, a foreign body reaction leading to ejection, or malfunctioning of the tag. We speculate that logger loss was related to a foreign body reaction, and that loggers were either rejected through the incision wound or, in the case of temperature loggers, possibly adhered and encapsulated to intestines, and then engulfed by the gastro-intestinal tract and ejected. We discuss animal welfare implications and give recommendations for future studies implanting bio-loggers into wildlife.

\section{Background}

Passive integrated transponder devices (PIT tags; also known as 'microchips') are valuable for individual identification of animals and are widely used for studying animal ecology and behavior $(1,2)$. Similarly, the surgical implantation of very high frequency (VHF) transmitters, or temperature, and heart rate biologgers, can provide highly useful data on animal location, physiological parameters, and behavior (3-7). This is especially true for cryptic species that are hard to monitor and observe directly, such as nocturnal animals.

Intra-peritoneal bio-loggers are used in physiological field research worldwide, with an increased frequency over the last decade (7-9). Several mammal studies have used either subcutaneous or intra- 
peritoneal loggers $(3,10-12)$. Most studies have reported successful results without complications, whereas others document varying tissue responses. A study on brown bears (Ursus arctos) reported corrosion of parts of implanted devices and leakage from short-circuited batteries, which resulted in the death of two study animals (11). The same study found a varying degree of tissue foreign body reaction to the implanted devices, ranging from no reaction to light encapsulation to thick capsule formation.

Additionally, the implantation process and associated anesthesia can cause complications, e.g. due to circulatory failure (13), and more generally the capture process can be highly stressful for the studied animals (14-16). Thus, to avoid unnecessary recapture of study animals, PIT tags and bio-loggers should function for long periods of time, and their functionality and retention should be tested. For example, a study on American black bears (Ursus americanus) found that 5 of 6 , including 2 of 2 intraperitoneal and 3 of 4 subcutaneous devices, were rejected, potentially due to foreign body responses (17). Similarly, 25 of 39 subcutaneous implants were rejected prematurely (between 2 and 198 days) in American black bear cubs (18).

Here, we evaluated the retention of PIT tags, implanted VHFs, and bio-loggers that were either implanted subcutaneously or into the peritoneal cavity of Eurasian beavers (Castor fiber, hereafter beaver). Beavers are large semiaquatic rodents. They are sexually monomorphic and nocturnal, which usually makes visual identification of unmarked individuals impossible (apart from tail scar identification). Thus, apart from ear tagging $(19,20)$, PIT tagging is a widespread technique to mark and identify individuals $(21,22)$, and might allow for remote monitoring of beavers (23). Moreover, the implantation of VHF transmitters was previously used to study the movement of beavers (13). However, to our knowledge, this is the first study describing the implantation and retention of body temperature loggers and insertable cardiac monitors (measuring heart rate) in beavers.

\section{Methods}

\section{Study areas, beaver captures, and PIT tagging}

We captured beavers in two study areas in Norway, located around $B \emptyset$, Vestfold and Telemark County $\left(59.38^{\circ} \mathrm{N}, 9.17^{\circ} \mathrm{E}\right)$ and around Evenstad, Innlandet County $\left(61.42^{\circ} \mathrm{N}, 11.09^{\circ} \mathrm{E}\right)$, with permission from the relevant authorities and the local landowners (see ethics approval). The first study area consisted of three medium sized rivers (for details see 24), and the second area of the large river Glomma. Only the first area was used for the PIT tag part of this study, because this was our long-term study area where we studied beavers since 1997 (beavers in Evenstad were only recaptured to retrieve temperature and heart rate loggers; see below). Beavers were captured from a motorboat at night, using spotlights and landing nets (25). All newly captured individuals were implanted with a PIT tag (iTag162, BTS-ID, Helsingborg, Sweden) that was implanted subcutaneously in the dorsal midline neck region with a specialized needle (NE-100/162, BTS-ID) and implanter (IMP-90pit, BTS-ID), and with unique ear-tags (26). All PIT tags were checked for functionality upon implantation. Moreover, we recorded tail scars using a field sheet. Individuals were sexed based on the color and viscosity of their anal gland secretion (27). The age of 
individuals first captured as kit or yearling was determined based on body mass (28), and we classified beavers first captured as adults, as minimum two years old when they had a mass $\geq 17 \mathrm{~kg}$ and $\leq 19.5$ $\mathrm{kg}$, or as minimum three years when $>19.5 \mathrm{~kg}$ at the time of first capture (26). We categorized beavers into kits (first year of life), yearlings (second year of life), 2-3 year old, and $\geq 4$ year old, because growth rates differ between these age classes (29). Upon each recapture, we used a scanner (MiniTracker 3, Avid Identification Systems, Inc., Norco, USA) to detect the PIT tag. The PIT tag was considered malfunctioning or lost if not detectable after we scanned the entire body of the beaver.

\section{Implantation and retrieval of bio-loggers}

In August 2015 and October 2016 we implanted 36 body temperature loggers in 28 beavers ( 8 individuals received a second temperature logger after the first one was removed/not recovered), with 18 of these individuals also receiving 21 cardiac monitors (hereafter heart rate loggers; 3 individuals received two heart rate loggers; Table 1, Table S1 and Table S2). We used two temperature logger models (DST centi-T, ceramic and epoxy coating, diameter $\times$ length: $15 \times 46 \mathrm{~mm}$, weight: $19 \mathrm{~g}$ or DST micro-T, $8.3 \times 25.4 \mathrm{~mm}$, $3.3 \mathrm{~g}$; both produced by Star-Oddi, Garðabær, Iceland), and three heart rate logger models (Reveal DX and $\mathrm{XT}$, both having the same coating of titanium, silicone, and parylene, dimensions of both: $8 \mathrm{~mm} \times 19 \mathrm{~mm}$ x $62 \mathrm{~mm}, 15 \mathrm{~g}$; and Reveal LINQ, titanium coating, $4.0 \mathrm{~mm} \times 7.2 \mathrm{~mm} \times 44.8 \mathrm{~mm} ; 2.4 \mathrm{~g}$; all Medtronic Inc., Minneapolis, Minnesota, USA). In the Evenstad population, no prior marked (ear-tagged or PIT-tagged) individuals were available, and we implanted free floating VHF transmitters (model 1245B, diameter $\times$ length: $20 \mathrm{~mm} \times 70 \mathrm{~mm}$, weight: $40 \mathrm{~g}$, Advanced Telemetry Systems, Isanti, Minnesota, USA) into the peritoneal cavity to facilitate recapture. After capture, beavers were transported in cloth sacks to the veterinary processing area. Anesthesia was induced with intramuscular medetomidine $(0.05 \mathrm{mg} / \mathrm{kg}$, Domitor vet $1 \mathrm{mg} / \mathrm{ml}$, Orion Pharma), butorphanol (0.1 mg/kg, Butomidor® vet $10 \mathrm{mg} / \mathrm{ml}$, Richter Pharma), ketamine ( $5 \mathrm{mg} / \mathrm{kg}$, Narketan ${ }^{\circledR} 100 \mathrm{mg} / \mathrm{ml}$, Vetoquinol), and midazolam $(0.24 \mathrm{mg} / \mathrm{kg}$ Midazolam B Braun $5 \mathrm{mg} / \mathrm{ml}$ ). We did not use choral hydrate or chloroform for anesthesia, or any chemical containing ether. After induction of anesthesia, all beavers received meloxicam $(0.2 \mathrm{mg} / \mathrm{kg}$ Metacam $5 \mathrm{mg} / \mathrm{ml}$, Boehringer Ingelheim), and intra-nasal oxygen $0.5 \mathrm{~L} / \mathrm{min}$; via oxygen bottle or via an

oxygen concentrator (setting $4.5-6$, Eclipse $5^{\text {TM }}$ auto SAT ${ }^{\circledR}$ SeQual, Medtek.no). For surgery, individuals were put in dorsal recumbency. An area caudal to the umbilicus (approx. $6 \times 4 \mathrm{~cm}$ ) was clipped and surgically prepared with chlorhexidine in $60 \%$ ethyl alcohol (Klorhexidinsprit $5 \mathrm{mg} / \mathrm{ml}$ Fresenius Kabi). For access to the peritoneal cavity, an approximately $4 \mathrm{~cm}$ long ventral midline incision through the Linea alba was made using standard surgical techniques. Temperature loggers and VHF transmitters were gas sterilized using ethyline oxide gas. VHF transmitters and temperature loggers were placed in the peritoneal cavity and sutured to the ventral body wall at the level of the umbilicus using non-absorbable suture material (Prolene ${ }^{\mathrm{TM}}$, Ethicon). The incision was closed in two-three layers (Linea alba, subcutaneous tissue when sufficient, and skin) with absorbable suture material (PDS ${ }^{T M}$ II, Ethicon), using a simple interrupted pattern for the Linea alba (US 0; with a round needle), a simple continuous pattern using the same suture for the subcutaneous layer, and finally an intradermal or interrupted horizontal mattress pattern for the skin (US 2-0, cutting needle) The skin incision was covered with a spray dressing (OPSITE, Smith \& Nephew Medical Ltd). Heart rate loggers were inserted through a $1-2 \mathrm{~cm}$ incision 
(depending on device size) subcutaneously on the left lateral thorax at the level of the heart. The skin was closed with intra-dermal sutures (PDS US 2-0). Surgeries for implanting both loggers lasted for $21 \pm 6$ minutes (mean $\pm S D$ ). Retrieving loggers at recapture followed the same procedure, except surgery times lasted $37 \pm 19$ minutes and abdominal incision lengths were approximately $2 \mathrm{~cm}$ longer, as device removal took more space. After surgery ended, anesthesia was partially antagonized with intramuscular atipamezole $(0.25 \mathrm{mg} / \mathrm{kg}$, Antisedan $5 \mathrm{mg} / \mathrm{ml}$, Orion Pharma). Beavers were released close to the main lodge of their own territory once they were fully recovered, typically $4 \mathrm{~h}$ post-surgery. Approximately six months to one-year post-surgery, we attempted to recapture the beavers to download heart rate logger data and to remove the temperature loggers. The downloading of heart rate logger data was performed using a transcutaneous telemetry system with beavers restrained in a cloth sack without anesthesia (30). Temperature loggers had to be removed from the peritoneal cavity to access data. The anesthesia and removal of temperature loggers and VHF transmitters were conducted simultaneously. After 3 surgeries where loggers were not found, the remaining beavers were radiographed before the logger removal surgery to confirm if loggers were present (Fig. 1). When radiography showed that loggers were no longer present in a beaver's body, we did not conducted surgery. 
Table 1

Overview of the number of temperature loggers and heart rate loggers implanted in Eurasian beavers (Castor fiber) shown separately by sensor type, sex and fate.

\begin{tabular}{|c|c|c|c|c|}
\hline Sensor type/sex & Not recaptured & Lost/undetected & Recovered & Total \\
\hline \multicolumn{5}{|c|}{ Temperature loggers } \\
\hline Centi-T & 10 & 5 & 11 & 26 \\
\hline Female & 4 & 2 & 5 & 11 \\
\hline Male & 6 & 3 & 6 & 15 \\
\hline Micro-T & 3 & 4 & 3 & 10 \\
\hline Female & 2 & 1 & 2 & 5 \\
\hline Male & 1 & 3 & 1 & 5 \\
\hline Total & 13 & 9 & 14 & 36 \\
\hline \multicolumn{5}{|l|}{ Heart rate loggers } \\
\hline RVL-BW & 2 & 9 & 3 & 14 \\
\hline Female & & 4 & 2 & 6 \\
\hline Male & 2 & 5 & 1 & 8 \\
\hline RVL-XT & & & 3 & 3 \\
\hline Female & & & 2 & 2 \\
\hline Male & & & 1 & 1 \\
\hline Linq & 1 & 1 & 2 & 4 \\
\hline Female & & 1 & & 1 \\
\hline Male & 1 & & 2 & 3 \\
\hline Total & 3 & 10 & 8 & 21 \\
\hline
\end{tabular}

\section{Statistical analyses}

We analyzed the probability of PIT tag loss in a given year ( $1=$ lost versus $0=$ not lost; response variable) using a generalized linear mixed model of the R package Ime4 (31) with a binomial distribution, including, age class (yearling, 2-3 year old, $>3$ year old) and sex as fixed effects and beaver ID as random intercept. Kits were excluded from this analysis, because they never lost a PIT tag (see results). For temperature and heart rate loggers, we also analyzed the probability of logger loss (two separate analyses) using a generalized linear model with a binomial distribution. We included sex and the sensor type as independent variables. We included sensor type to test the hypothesis that the size of the logger (which 
differed between models) affects the probability of logger retention. We did not include age, because all individuals that received a temperature or heart rate logger were adult ( $\geq 2$ years old), and in order to avoid overfitting our statistical models due to the small sample size. For all analyses, we selected the most parsimonious model based on AIC, by comparing the full model, single effects models, and the intercept only model using the R package 'MuMIn' (32; Table 2). If two or more models had AIC values within delta AIC $<2$, we selected the simpler model (33). Validation of the most parsimonious model was made by visual inspection of residuals (34). Model estimates that included zero within their $95 \%$ confidence interval were considered uninformative (35). All statistical analyses were carried out in R 4.0.3 (36).

Table 2

The model selection results for the analyses investigating the probability of (1) PIT tag loss, (2) temperature logger loss, and (3) heart rate logger loss, showing the used degrees of freedom (df), log likelihood (logLik), AIC , delta AIC, and AIC weight. Models were ranked by $\mathrm{AlC}_{\mathrm{C}}$.

\begin{tabular}{|lccccc|}
\hline Model & df & logLik & AICc & delta AIC & AIC weight \\
\hline (1) PIT tag loss & & & & & \\
\hline Intercept only & 2 & -114 & 231 & 0.00 & 0.484 \\
\hline Sex & 3 & -113 & 232 & 1.05 & 0.286 \\
\hline Age class & 4 & -113 & 234 & 2.44 & 0.143 \\
\hline Age class + Sex & 5 & -112 & 235 & 3.44 & 0.087 \\
\hline (2) Temperature logger loss & & & \\
\hline Intercept only & 1 & -15 & 33 & 0.00 & 0.451 \\
\hline Sensor type & 2 & -15 & 34 & 1.06 & 0.266 \\
\hline Sex & 2 & -15 & 35 & 1.78 & 0.185 \\
\hline Sensor type + Sex & 3 & -14 & 36 & 3.07 & 0.097 \\
\hline (3) Heart rate monitor loss & & & \\
\hline Intercept only & 1 & -12 & 27 & 0.00 & 0.564 \\
\hline Sensor type & 2 & -12 & 29 & 1.83 & 0.226 \\
\hline Sex & 2 & -12 & 30 & 2.55 & 0.157 \\
\hline Sensor type + Sex & 3 & -12 & 32 & 4.73 & 0.053 \\
\hline
\end{tabular}

\section{Results}




\section{PIT tags}

From 1997-2017, we captured 456 individuals between 1 and 24 times (mean \pm SD: $3.1 \pm 3.3$; median: 2), totaling 1,391 capture events. We removed captures of the same individual within the same year to avoid pseudoreplication, leaving 1,039 capture events. Of those, we failed to detect a PIT tag in 30 cases (2.9\% of annual capture events and $6.6 \%$ of all individuals). Consequently, we implanted a new PIT tag in these individuals, i.e., 26 individuals 'lost' their PIT tag 1-3 times (mean \pm SD: $1.2 \pm 0.5$ ). In all instances we were still able to identify the individual due to the presence of unique ear tag numbers and tail scars. We implanted PIT tags in 105 kits captured for the first time, and always detected the PIT tag when recapturing these individuals within their first year of life (51 recaptures). We failed to detect PIT tags in 10 individuals out of 87 yearlings (11.5\%), 10 cases (8 individuals) out of $1902-3$ year olds (5.3\%), and 10 cases ( 8 individuals) out of $74 \geq 4$ year old individuals (13.5\%). When calculating the rate of PIT tag disappearance per beaver year, PIT tag disappearance was $0.0 \%$ in kits, $7.0 \%$ in yearlings (i.e., in the year from being a kit to being a yearling), $2.9 \%$ in $2-3$ year olds, and $2.6 \%$ in $\geq 4$ year olds. Of the 30 PIT tag disappearances, 8 were in females ( 5 in yearlings, 1 in 2-3 year old, and 2 in $\geq 4$ year olds) compared to 22 in males ( 5 in yearlings, 9 in 2-3 year old, and 8 in $\geq 4$ year olds). The overall sex ratio in our study population was even ( 223 females, 233 males). The annual probability of PIT tag loss was best explained by the intercept only model (Table 2). However, when considering the full model, annual probability of PIT tag loss was higher in yearlings compared to older individuals, and tended to be higher in males compared to females (Fig. 2, Table S3). The percentage of PIT tag disappearance also varied among years, from 0 to $9.5 \%$ (mean \pm SD: $3.0 \pm 2.9 \%$ ), being $>5 \%$ in 6 out of 21 years.

\section{Temperature loggers, heart rate loggers and VHFs}

Of the 36 temperature loggers that we implanted into beavers (Table 1, Table S1), we could subsequently retrieve 13 loggers by recapturing individuals and one from a dead beaver that was shot by a hunter. The presence of the temperature logger was confirmed by using radiography in 5 individuals (we did not have access to radiography equipment during the other recaptures). In addition, in 9 recaptured beavers, we failed to recover the temperature logger, and the loss of loggers was confirmed by radiography in 6 cases (radiography equipment was not available in the other recaptures). Finally, 13 loggers were not retrieved, because we failed to recapture the beaver (Table 1). The probability of temperature logger loss (in the 23 cases when we recaptured beavers) was best explained by the intercept only model (Table 2), and logger type and sex were uninformative in explaining logger loss in the full model (Table S4).

Of the 21 beavers with heart rate loggers, we could recapture 18 individuals between 1 and 6 times, and managed to download data from 8 heart rate loggers (Table 1, Table S2). For 10 individuals, we could confirm that they had lost the heart rate logger; for 3 of these individuals we were able to confirm presence of the logger prior to the loss (after a period of 3-6 months from logger implantation; Table S2). Due to the subcutaneous location of the heart rate logger we were able to confirm its presence or absence by palpation. Three beavers could not be located and recaptured (Table 1, Table S2). The probability of heart rate logger loss (in the 18 cases when we recaptured beavers) was best explained by the model 
including the sensor type, but this model was within delta AIC $<2$ of the intercept only model (Table 2). Moreover, sensor type and sex were uninformative in explaining logger loss in the full model (Table S4) and in the model including sensor type.

Of the 6 beavers with VHF units implanted, we recaptured 2 and retrieved their VHF units (no other individuals with an implanted VHF were recaptured). Expected battery life was 540 days (at 40 beats per minutes and $20 \mathrm{~ms}$ signal length) but neither unit pulsed a signal 381 days after implantation. The VHF units were regularly monitored post implantation for up to 192 days when ice covered the river in midNovember. Signal strength was weak when beavers where below ground and disappeared with the ice and snow cover. No signals were present one-year post implantation either due to unit failure, empty battery or due to the beavers leaving the study area.

One of the beavers died during anesthesia prior to surgery for logger retrieval. The postmortem examination revealed severe cardiac compromise due to moderate dilated cardiomyopathy and myocardial fibrosis, most likely leading to death due to cardiac failure during induction. Necropsy revealed that the body temperature logger and VHF implant were present, and the heart rate logger was lost. To the best of our knowledge, no other beaver in this study was injured during capture and handling.

\section{Discussion}

\section{PIT tags}

The overall rate of PIT tag retention in our study was high, as shown for other species (37), emphasizing that they are a useful and reliable tool to mark individuals. Additional marking methods, such as ear tags or characteristic body markings/coloration $(19,38)$, can be used as a security mechanism to ensure accurate identification of individuals. Individual marking with a PIT tag or ear tags alone would have, in some instances, resulted in our inability to identify individuals after some years.

The analysis investigating the probability of PIT tag loss was best explained by the intercept only model, cautioning against inferring too much from the model suggesting a significant effect of age on the probability of tag loss. Nevertheless, the raw data on annual PIT tag loss suggests that PIT tags were ca. 2-times more often rejected in the year between first capture as a kit and the next capture as a yearling, compared to older individuals. PIT tags were also lost in older individuals, but these individuals were present in our study for much longer, and thus, the disappearance rate per year was much lower in older beavers compared to yearlings. Our personal experience is that kits were harder to implant with PIT tags compared to older individuals, potentially because the skin is less elastic with a smaller subcutaneous space for PIT tag placement. Thus, we speculate that the main cause for PIT tag disappearance was incorrect implantation technique, with PIT tags positioned too close to the skin entry site, and subsequently ejected. This could also explain the variation in the rate of PIT tag loss among years, i.e., when new personnel with less experience joined the project. An alternative explanation could be the large growth from kit to yearling, compared to older individuals. This might have either led to the ejection of the 
PIT tag or the movement of the PIT tag to another position in the body, as shown in other species (39), consequently not being detected by us. However, we scanned the entire beaver body when we did not detect the PIT tag in the neck, but failed to detect PIT tags in other body regions. We also have limited evidence that more males (22) than females (8) lost PIT tags. However, our low sample size of lost tags cautions against a general interpretation of this finding. We cannot exclude the possibility that failure to detect PIT tags, especially in older individuals, might be caused by the failure of the PIT tag (40).

\section{Temperature loggers, heart rate loggers and VHF}

In the 23 instances where we recaptured beavers, 14 temperature loggers were retrieved from the peritoneal cavity, while 9 loggers were not found, in spite of radiographing beavers in 6 of these cases. This suggests that the logger had been lost by the beaver. Similarly, the fact that ca. half of all beavers lost their heart rate logger suggests that the logger or the suture material caused a foreign body reaction by the beavers' immune system, resulting in loss of the heart rate logger. Implant loss was also reported for American black bears, where both subcutaneous and intraperitoneal bio-loggers were externalized $>44$ days post-implantation (17), with fewer rejections occurring in subsequent studies that used the smaller 'Reveal LINQ' heart rate model (41). We found no differences among models (that markedly differed in size), which does not support the idea that smaller loggers are more likely to be rejected. However, we only implanted 3 'LINQ' heart rate loggers, a sample size too small to make a reliable comparison between heart rate logger models. For the VHF, two animals were recaptured, and both had the VHF in place.

Most likely, the loss of subcutaneous heart rate loggers was due to a foreign body reaction to either the logger or the suture material used. Suture material takes 180-210 days for complete absorption (42), which spans most of the timespan for observed logger loss. One beaver had edema around the spot where the logger had previously been at recapture ( $>6$ months after implantation), indicating recent loss and making a foreign body reaction likely. The fact that beavers were swimming shortly after recovery, before the surgical wound was healed, could be a contributing factor. However, other aquatic species have received surgical bio-loggers, without this complication (43). Potential breaches in surgical sterility during field procedures might have increased the risk of bacterial engraftment on biomaterials, potentially leading to increased susceptibility to infections (44). Consequently, infections in the fresh wounds might have resulted in the rejection of subcutaneous heart rate loggers through the incision wound. This idea does not hold for the three beavers that still had the heart rate logger at the first recapture and where logger loss was documented at a subsequent capture, as normal incision healing should occur within two weeks. Finally, intraspecific aggression and wounding other beavers would be a possible mechanism (21, 45), where trauma and/or infected surgical wounds resulted in subcutaneous bio-logger loss. This latter mechanism might explain the loss of subcutaneous heart rate loggers that, in at least 3 instances, were lost after the wound was healed, because we managed to successfully download data ca. 2 months after surgery, and the individuals then lost the heart rate logger later.

For intra-abdominal temperature loggers, the loss is even more unusual. One speculation is that the temperature loggers underwent a foreign body reaction in close proximity to the gastro-intestinal tract, 
and were first adhered to, then engulfed by and then ejected into the gastro-intestinal tract. This has been observed in sheep (Ovis aries) with implanted peritoneal loggers (9). Similarly, externalization of transmitters implanted in the peritoneal cavity was reported for channel catfish (Ictalurus punctatus), where transmitters had been expelled in more than half of the implanted fish within 23 days postimplantation, either through the intestine, through the incision, or (in one case) through a lesion in the ventral body wall (46). Transmitter loss was also reported for birds and reptiles $(47,48)$. In contrast, in a study implanting 305 brown bears with VHF transmitters reported no loss (11). These contrasting findings indicate that species differences (physiology, immune system etc.) might play a role regarding device loss. Moreover, implantation procedures, the coating material of implants, and suture material may play a role in wound healing and foreign body reactions (49). We argue that using a suture type with a longer holding power (such as Maxon, or PDS, as used here) is appropriate due to the Linea alba's longer time for healing than other tissue types (18-21 days). The prolene sutures, used to tack the logger to the body wall, could be avoided in future studies, either allowing the temperature loggers to be free-floating or by using a faster absorbing suture. There are species differences in reactivity to foreign bodies. Although beavers are poorly studied in this respect, studies in laboratory rodents found that Maxon and PDS were less reactive than some alternatives, including Vicryl (commonly used in veterinary medicine) (42). The sutures monocryl and biosin were less reactive than PDS. As these sutures are absorbed in 90-120 days (vs 180-210 days for PDS), they would be a good alternative for skin sutures (for subcutaneous device closure and for closure of the skin layer after abdominal closure with suture such as PDS). Another factor is the thickness of the suture, because tissue reactivity increases with increasing suture size (50), and larger suture sizes decrease the amount of bacteria needed for a wound to get infected (51). Experience from other species indicates that smaller sutures (2-0 PDS for Linea alba closure and 3-0 to 4-0 for skin closure) would most likely be sufficient.

\section{Conclusions}

In conclusion, we can confirm that PIT tags are generally reliable for tagging wild animals that are hard to distinguish under field conditions. As PIT tag loss (either due to incorrect implantation or rejection by the beavers immune system) or failure (malfunctioning of the tag) might occasionally occur, we advocate for a combination of PIT tags with other indirect or direct methods, such as ear tagging or the recording of individual marks (e.g. tail scars in the case of beavers). Only the combination with ear tags (that are lost more frequently than PIT tags) and recording of tail scars (that change over time) allowed us to reliably identify $>450$ individuals over $>20$ years of the Norwegian beaver project. To minimize possible PIT tag ejection, the puncture wound could be sealed using tissue adhesive (52). Incorrect implantation technique was likely the main cause for PIT tag loss, making adequate training of staff a priority to improve tag retention.

The high proportion of temperature and heart rate logger loss has animal welfare implications, because many study animals underwent surgery without subsequently providing information, consequently increasing the number of study animals needed to obtain statistically sound data. Thus, future studies should aim to increase both the recapture rate as well as develop mechanisms that ensure improved 
implant retention. Moreover, we recommend that future studies in new species test all devices in captivity (e.g. zoos) to ensure post-surgery monitoring and secure data collection including testing of different suture materials for both efficacy and reactivity in that particular species. Finally, future studies should investigate if and how the coating material of implants affects foreign body reactions. To that end, bacterial cultures and histopathology of the tissues associated with foreign body reactions to loggers and sutures could add valuable information to improve the understanding of mechanisms responsible for bio-logger retention and loss.

\section{Declarations}

\section{Ethics approval and consent to participate}

Ethical committees within the Norwegian Food Safety Authority (most recent authorization FOTS ID 15947) and the Norwegian Directorate for Nature Management (most recent authorization 2014/14415 ART-VI-ID) approved this study, including all capture, handling and tagging procedures, and fieldwork was conducted with permission from the local landowners. All methods were carried out in accordance with relevant guidelines and regulations, complying with the ASAB/ABS Guidelines for the treatment of animals in behavioral research and teaching (53) and with the ARRIVE guidelines (54).

\section{Consent for publication}

Not applicable.

\section{Availability of data and materials}

All relevant data is provided in the supplementary material (Table S1 and Table S2).

\section{Competing interests}

The authors declare that they have no competing interests.

\section{Funding}

This study was partly funded by the funded by the FoU research and development grand.

\section{Authors' contributions}

M.M., A.L.E., B.F., J.M.A., C.A.R. and F.R. conceived the ideas. C.A.R., M.M., B.F., and F.R. captured beavers, and A.L.E., J.M.A., M.L., K.L.P., and E.M.G. performed surgeries and related veterinary tasks. T.G.L. provided bio-loggers. M.M. analyzed the data. M.M. and M.L. led the writing of the paper. All authors provided input to the manuscript and its revised versions.

\section{Acknowledgements}


We thank the many volunteers who assisted during fieldwork. Reveal DX/XT and LINQ bio-loggers were donated by Medtronic, Inc.

\section{References}

1. Gibbons WJ, Andrews KM. PIT tagging: simple technology at its best. Bioscience. 2004;54(5):44754.

2. Testud G, Vergnes A, Cordier P, Labarraque D, Miaud C. Automatic detection of small PIT-tagged animals using wildlife crossings. Animal Biotelemetry. 2019;7(1):1-9.

3. Græsli AR, Le Grand L, Thiel A, Fuchs B, Devineau O, Stenbacka F, et al. Physiological and behavioural responses of moose to hunting with dogs. Conservation Physiology. 2020;8(1):coaa122.

4. Sheppard JL, Arnold TW, Amundson CL, Klee D. Effects of surgically implanted transmitters on reproduction and survival in mallards. Wildlife Society Bulletin. 2017;41(3):597-604.

5. Pohlin F, Brabender K, Fluch G, Stalder G, Petit T, Walzer C. Seasonal variations in heart rate variability as an indicator of stress in free-ranging pregnant Przewalski's horses (E. ferus przewalskii) within the Hortobágy National Park in Hungary. Frontiers in physiology. 2017;8:664.

6. Moraes RN, Laske TG, Leimgruber P, Stabach JA, Marinari PE, Horning MM, et al. Inside out: heart rate monitoring to advance the welfare and conservation of maned wolves (Chrysocyon brachyurus). Conservation physiology. 2021;9(1):coab044.

7. Thiel A, Evans AL, Fuchs B, Arnemo JM, Aronsson M, Persson J. Effects of reproduction and environmental factors on body temperature and activity patterns of wolverines. Frontiers in zoology. 2019;16(1):1-12.

8. Trondrud LM, Pigeon G, Albon S, Arnold W, Evans AL, Irvine RJ, et al. Determinants of heart rate in Svalbard reindeer reveal mechanisms of seasonal energy management. Philosophical Transactions of the Royal Society B. 2021;376(1831):20200215.

9. Fuchs B, Sørheim KM, Chincarini M, Brunberg E, Stubsjøen SM, Bratbergsengen K, et al. Heart rate sensor validation and seasonal and diurnal variation of body temperature and heart rate in domestic sheep. Veterinary and Animal Science. 2019;8:100075.

10. Rutz C, Hays GC. New frontiers in biologging science. Biology letters. 2009;5(3):289-92.

11. Arnemo JM, Ytrehus B, Madslien K, Malmsten J, Brunberg S, Segerström P, et al. Long-term safety of intraperitoneal radio transmitter implants in brown bears (Ursus arctos). Frontiers in veterinary science. 2018;5:252.

12. Friebe A, Evans AL, Arnemo JM, Blanc S, Brunberg S, Fleissner G, et al. Factors affecting date of implantation, parturition, and den entry estimated from activity and body temperature in free-ranging brown bears. PloS one. 2014;9(7):e101410.

13. Ranheim B, Rosell F, Haga HA, Arnemo JM. Field anaesthetic and surgical techniques for implantation of intraperitoneal radio transmitters in Eurasian beavers Castor fiber. 2004. 
14. Mayer M, Haugaard L, Sunde P. Scared as a hare: effects of capture and experimental disturbance on survival and movement behavior of European hares. Wildlife Biology. 2021;2021(3):wlb. 00840.

15. Arnemo JM, Ahlqvist P, Andersen R, Berntsen F, Ericsson G, Odden J, et al. Risk of capture-related mortality in large free-ranging mammals: experiences from Scandinavia. Wildlife Biology. 2006;12(1):109-13.

16. Neumann W, Ericsson G, Dettki H, Arnemo JM. Effect of immobilizations on the activity and space use of female moose (Alces alces). Canadian journal of zoology. 2011;89(11):1013-8.

17. Laske TG, Harlow HJ, Werder JC, Marshall MT, laizzo PA. High Capacity Implantable Data Recorders: System Design and Experience in Canines and Denning Black Bears. Journal of Biomechanical Engineering. 2005;127(6):964-71.

18. Echols KN, Vaughan MR, Moll HD. Evaluation of subcutaneous implants for monitoring American black bear cub survival. Ursus. 2004;15(2):172-81.

19. Smith JB, Windels SK, Wolf T, Klaver RW, Belant JL. Do transmitters affect survival and body condition of American beavers Castor canadensis? Wildlife Biology. 2016;22(3):117-23.

20. Sharpe F, Rosell F. Time budgets and sex differences in the Eurasian beaver. Animal Behaviour. 2003;66(6):1059-67.

21. Mayer M, Aparicio Estalella C, Windels SK, Rosell FN. Landscape structure and population density affect intraspecific aggression in beavers. Ecology and Evolution. 2020;10(24):13883-94.

22. Mayer M, Zedrosser A, Rosell $F$. When to leave: the timing of natal dispersal in a large, monogamous rodent, the Eurasian beaver. Animal Behaviour. 2017;123:375-82.

23. Briggs AJ, Robstad CA, Rosell F. Using radio-frequency identification technology to monitor Eurasian Beavers. Wildlife Society Bulletin. 2021;45(1):154-61.

24. Haarberg O, Rosell F. Selective foraging on woody plant species by the Eurasian beaver (Castor fiber) in Telemark, Norway. Journal of Zoology. 2006;270(2):201-8.

25. Rosell F, Hovde B. Methods of Aquatic and Terrestrial Netting to Capture Eurasian Beavers. Wildlife Society Bulletin (1973-2006). 2001;29(1):269-74.

26. Campbell RD, Nouvellet P, Newman C, Macdonald DW, Rosell F. The influence of mean climate trends and climate variance on beaver survival and recruitment dynamics. Global Change Biology. 2012;18(9):2730-42.

27. Rosell F, Sun LX. Use of anal gland secretion to distinguish the two beaver species Castor canadensis and C. fiber. Wildlife Biology. 1999;5(2):119-23.

28. Rosell F, Zedrosser A, Parker H. Correlates of body measurements and age in Eurasian beaver from Norway. European journal of wildlife research. 2010;56(1):43-8.

29. Campbell R. Demography and life history of the Eurasian beaver Castor fiber. Unpublished D Phil thesisUniversity of Oxford. 2010.

30. Laske TG, Garshelis DL, laizzo PA. Monitoring the wild black bear's reaction to human and environmental stressors. BMC physiology. 2011;11(1):1-15. 
31. Bates D, Mächler M, Bolker B, Walker S. Fitting Linear Mixed-Effects Models Using Ime4. J Stat Soft. 2015;67(1):48.

32. Barton K. Package “MuMIn”: Multi-Model Inference. R package, Version 1.15. 6. 2016.

33. Harrison XA, Donaldson L, Correa-Cano ME, Evans J, Fisher DN, Goodwin CED, et al. A brief introduction to mixed effects modelling and multi-model inference in ecology. PeerJ. 2018;6:e4794.

34. Zuur AF, leno EN. A protocol for conducting and presenting results of regression-type analyses. Methods in Ecology and Evolution. 2016;7(6):636-45.

35. Arnold TW. Uninformative parameters and model selection using Akaike's Information Criterion. The Journal of Wildlife Management. 2010;74(6):1175-8.

36. R Core Team. R: A language and environment for statistical computing. 2013.

37. Borchert A, Davis JL, Barnes ME. Retention of Passive Integrated Transponders (PIT) Tags in Juvenile Rainbow Trout and Brown Trout. Journal of FisheriesSciences com. 2020;14(1):007-11.

38. Silvy NJ, Lopez RR, Peterson MJ. Techniques for marking wildlife. The wildlife techniques manual. 2012;1:230-57.

39. Wyneken J, Epperly SP, Higgins B, McMichael E, Merigo C, Flanagan JP. PIT tag migration in seaturtle flippers. Herpetological Review. 2010;41(4):448.

40. Rigby E, Aegerter J, Brash M, Altringham J. Impact of PIT tagging on recapture rates, body condition and reproductive success of wild Daubenton's bats (Myotis daubentonii). Veterinary Record. 2012;170(4):101-.

41. Laske TG, Garshelis DL, lles TL, laizzo PA. An engineering perspective on the development and evolution of implantable cardiac monitors in free-living animals. Philosophical Transactions of the Royal Society B. 2021;376(1830):20200217.

42. McFadden MS. Suture materials and suture selection for use in exotic pet surgical procedures. Journal of Exotic Pet Medicine. 2011;20(3):173-81.

43. Horning M, Haulena M, Tuomi PA, Mellish J-AE, Goertz CE, Woodie K, et al. Best practice recommendations for the use of fully implanted telemetry devices in pinnipeds. Animal Biotelemetry. 2017;5(1):1-15.

44. Londono R, Badylak SF. Factors which affect the host response to biomaterials. Host response to biomaterials: Elsevier; 2015. p. 1-12.

45. Crawford JC, Bluett RD, Schauber EM. Conspecific Aggression by Beavers (Castor canadensis) in the Sangamon River Basin in Central Illinois: Correlates with Habitat, Age, Sex and Season. The American Midland Naturalist. 2015;173(1):145-55.

46. Marty GD, Summerfelt RC. Pathways and mechanisms for expulsion of surgically implanted dummy transmitters from channel catfish. Transactions of the American Fisheries Society. 1986;115(4):57789.

47. Malachowski CP, Dugger BD, Heard DJ. Extrusion of Intracoelomic Radiotransmitters by Hawaiian Ducks. Wildlife Society Bulletin. 2020;44(4):741-8. 
48. Pearson DJ, Shine R. Expulsion of intraperitoneally-implanted radiotransmitters by Australian pythons. Herpetological Review. 2002;33(4):261-2.

49. Marcec R, Kouba A, Zhang L, Zhang H, Wang Q, Zhao H, et al. Surgical implantation of coelomic radiotransmitters and postoperative survival of Chinese giant salamanders (Andrias davidianus) following reintroduction. Journal of Zoo and Wildlife Medicine. 2016;47(1):187-95.

50. Van Rijssel E, Brand R, Admiraal C, Smit I, Trimbos J. Tissue reaction and surgical knots: the effect of suture size, knot configuration, and knot volume. Obstetrics and gynecology. 1989;74(1):64-8.

51. Mayhew P. Sutures, Needles, and Suture Patterns: All You Ever Needed to Know. World Small Animal Veterinary Association Congress Proceedings. 2019.

52. Lebl K, Ruf T. An easy way to reduce PIT-tag loss in rodents. Wiley Online Library; 2010. Report No.: 0912-3814.

53. ASAB/ABS. Guidelines for the treatment of animals in behavioural research and teaching. Anim Behav. 2020;159:I-XI.

54. Percie du Sert N, Ahluwalia A, Alam S, Avey MT, Baker M, Browne WJ, et al. Reporting animal research: Explanation and elaboration for the ARRIVE guidelines 2.0. PLOS Biol. 2020;18(7):e3000411.

\section{Figures}

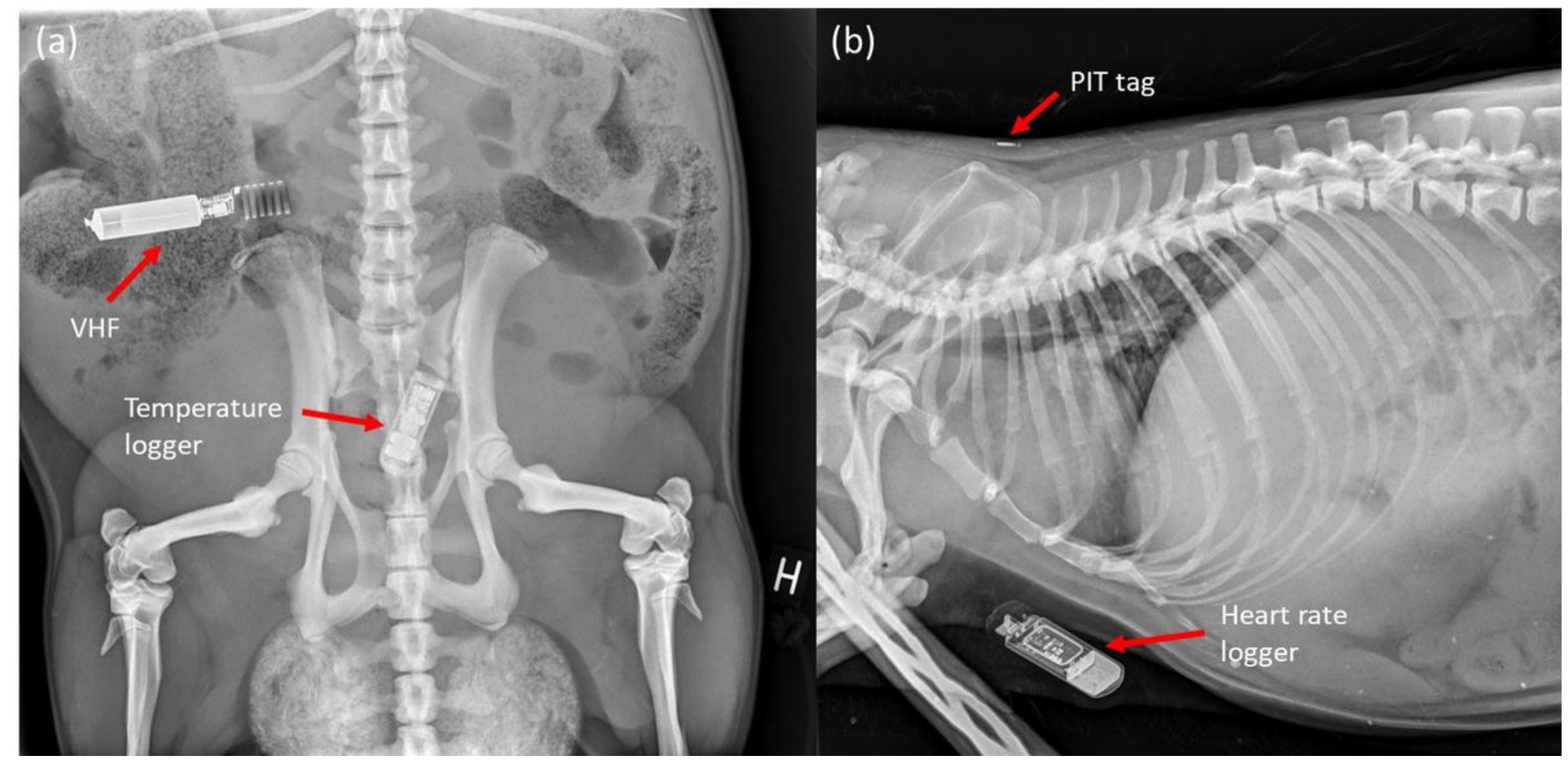

\section{Figure 1}

Dorsoventral and right lateral radiographs of two Eurasian beavers (Castor fiber) demonstrating the location of (a) a temperature logger (center) and VHF (top left) within the peritoneal cavity, and (b) a 
subcutaneous heart rate logger (bottom) and a subcutaneous PIT tag (top).

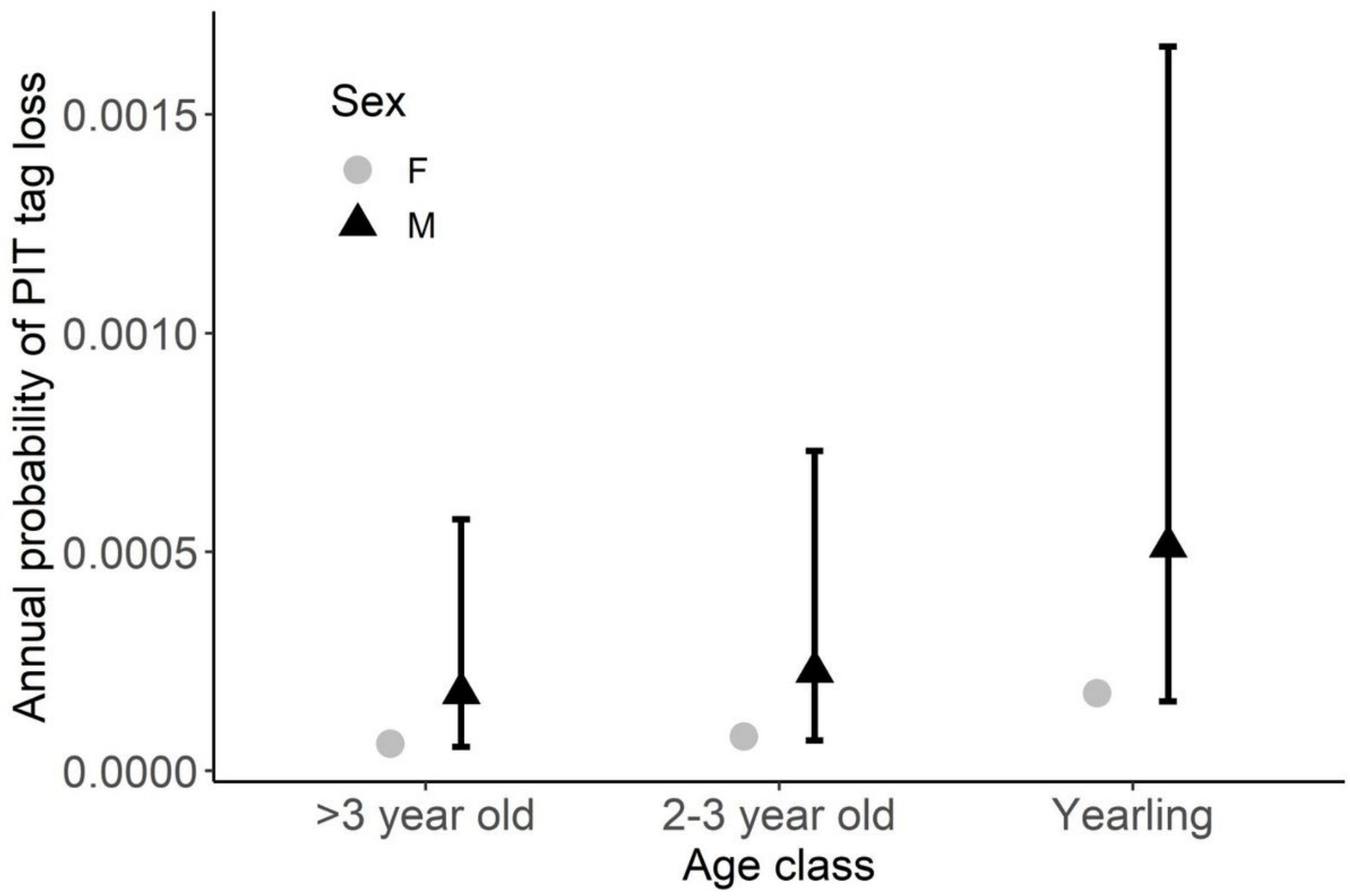

Figure 2

The annual probability of PIT tag loss in Eurasian beavers (Castor fiber), separately by age class and sex (grey dots $=$ female, black triangles $=$ male). Bars show 95\% confidence intervals.

\section{Supplementary Files}

This is a list of supplementary files associated with this preprint. Click to download.

- Supplementarymaterial.docx 